\title{
Use of gene-editing technology to introduce targeted modifications in pigs
}

\author{
Junghyun Ryu', Randall S. Prather ${ }^{2,3}$ and Kiho Lee ${ }^{1 *}$
}

\begin{abstract}
Pigs are an important resource in agriculture and serve as a model for human diseases. Due to their physiological and anatomical similarities with humans, pigs can recapitulate symptoms of human diseases, making them a useful model in biomedicine. However, in the past pig models have not been widely used partially because of the difficulty in genetic modification. The lack of true embryonic stem cells in pigs forced researchers to utilize genetic modification in somatic cells and somatic cell nuclear transfer (SCNT) to generate genetically engineered (GE) pigs carrying site-specific modifications. Although possible, this approach is extremely inefficient and GE pigs born through this method often presented developmental defects associated with the cloning process. Advancement in the gene-editing systems such as Zinc-Finger Nucleases (ZFNs), Transcription activator-like effector nucleases (TALENs), and the Clustered regularly interspaced short palindromic repeat (CRISPR)/CRISPR-associated 9 (Cas9) system have dramatically increased the efficiency of producing GE pigs. These gene-editing systems, specifically engineered endonucleases, are based on inducing double-stranded breaks (DSBs) at a specific location, and then site-specific modifications can be introduced through one of the two DNA repair pathways: non-homologous end joining (NHEJ) or homology direct repair (HDR). Random insertions or deletions (indels) can be introduced through NHEJ and specific nucleotide sequences can be introduced through HDR, if donor DNA is provided. Use of these engineered endonucleases provides a higher success in genetic modifications, multiallelic modification of the genome, and an opportunity to introduce site-specific modifications during embryogenesis, thus bypassing the need of SCNT in GE pig production. This review will provide a historical prospective of GE pig production and examples of how the gene-editing system, led by engineered endonucleases, have improved GE pig production. We will also present some of our current progress related to the optimal use of CRISPR/Cas9 system during embryogenesis.
\end{abstract}

Keywords: CRISPR/Cas9, Gene-editing, Genetic engineering, Knock-in, Knockout, Pig, TALEN, ZFN

\section{Background}

Genetically engineered (GE) animals have been an essential resource in advancing the biomedicine field. Traditionally, GE mouse models have been widely used because of the ability to engineer their genome through gene targeting and produce GE mice carrying site-specific modifications by using embryonic stem (ES) cells [1]. The mouse models are advantageous as they can be effectively managed and bred due to their size and life span. However, these mouse models cannot represent symptoms of certain human diseases, probably because of anatomic and physiological differences between mice and humans. The pig models, on

\footnotetext{
* Correspondence: kiholee@vt.edu

'Department of Animal and Poultry Sciences, Virginia Tech, 175 W. Campus Drive, Blacksburg, VA 24061, USA

Full list of author information is available at the end of the article
}

the other hand, can closely recapitulate the phenotype of many human diseases due to similar physiology, anatomy, immunology, and metabolic features compared to humans $[2,3]$. For instance, GE pigs carrying mutated CFTR genes present similar symptoms of human CFTR patients [4], where GE CFTR mouse models do not show these phenotypes. Although the benefit of using large animal models, such as pigs, in biomedicine is well-recognized, one of the major problems of applying pig models in biomedicine is inefficiency in genetic engineering technology. Because of the lack of ES cells, traditional GE pigs are produced by introducing targeted modifications in somatic cells, then generating GE pigs through somatic cell nuclear transfer (SCNT). A few breeding steps are required to generate animals with homozygous mutations because only heterozygous mutated pigs were produced due to the low efficiency 
of traditional gene targeting. However, considering the gestation period of pigs and time to reach sexual maturity, generating homozygous GE pigs has been expensive and can take several years. Development of engineered endonucleases now allows us to overcome these shortcomings. The endonucleases have shown to increase the targeting efficiency significantly and multiallelic modifications can be introduced into somatic cells $[5,6]$. In addition, direct injection of engineered endonucleases, for example CRISPR/Cas9, can disrupt multiple genes during embryogenesis [7-9]. The use of GE pigs has been concentrated in biomedicine due to available resources; however, the development of engineered endonucleases now expands their application beyond biomedicine. This review will focus on the historical aspects of pig models and how recent technologies have changed the potential uses of pig models in research.

\section{Historical approach of generating genetically engineered pigs}

For a complete understanding of how a biological system works it is necessary to dissect and manipulate the system. That manipulation can include altering the genome. It should be noted that the genomes of domestic animals, pigs in particular, have been altered by man for millennia. Selective breeding of cattle, for example, has resulted in animals that are more suited to milk production or to meat production. In pigs over just the past 50 years we have gone from a 'lardy' type pig to a highly productive, very prolific, long lean animal. These changes in phenotype in both cattle and pigs have been brought about by selection of natural variation already present in the population. Genetic engineering is the logical next step. The beginning of intentional genetic change mammals was reported as long ago as 1971 [10]. While viral mediated transgenesis was developed first [11], a more widely used genetic engineering technology was that of pronuclear injection [12]. Pronuclear injection was technically easier than viral transduction and very large constructs could be integrated into the genome. Pronuclear injection is a powerful tool to ask questions about the function of transgenes. Theoretically, any protein can be expressed at any level, compatible with development, in any cell type. Pronuclear injection does, however, have limitations that include: lack of control over the site of integration (e.g. possibly introducing an insertional knockout such as situs inversus [13], and lack of control of the number of copies of the gene that integrate. Nevertheless, pronuclear injection was used to create numerous lines of pigs [14-16]. A more precise method of altering the genome was introduced with homologous recombination [17]. In mice, the homologous recombination technology was used in conjunction with the newly discovered embryonic stem cells that could contribute to the germ line. This technology continues to be used in an attempt to knockout every single gene in the mouse [18]. Knock out of a gene unambiguously defines its function, and thus a better understanding of how the biological system functions can be obtained.

Unfortunately, despite concerted efforts [19-22], a suitable stem cell line has not been identified in the pig. Thus making a knockout in pigs was problematic. In parallel to the development of the embryonic stem cell technology, nuclear transfer was developed in domestic animals (sheep [23], cattle [24], pigs [25]. Extension of these early experiments that used donor nuclei from cleavage stage embryos led to later stages of embryos such as the inner cell mass of blastocyst stage embryos [26] to fetal derived fibroblast cells [27] to adult derived cells [28]. Since somatic cells could be grown in vitro and then used for somatic cell nuclear transfer, genetically engineering them prior to nuclear transfer would result in that particular genetic modification in the offspring. This was first demonstrated in sheep [29, 30] and then in pigs by introduction of a transgene [31] and the knockout of an endogenous gene [32]. To date a large number of transgenes have been added to pigs and a large number of genes have been knocked out [3, 33, 34]. However, efficiency of the entire procedures was extremely poor until the development of engineered endonucleases such as Zinc-Finger Nucleases (ZFNs), Transcription activator-like effector nucleases (TALENs), and Clustered regularly interspaced short palindromic repeat (CRISPR)/CRISPR-associated 9 (Cas9) system.

\section{Mechanism of engineered endonucleases}

To-date, three types of engineered endonucleases, ZFNs, TALENs, and CRISPR/Cas9 system, have been developed to facilitate genetic engineering process. The specific content of each engineered endonuclease will be introduced in following paragraphs. All three engineered endonucleases have DNA binding ability and utilize DNA double-strand break (DSB) as a means to introduce targeted modifications into the genome. The endonucleases are designed to introduce DSBs on a specific location in the genome as a molecular DNA scissors. Then, the DSBs will trigger the endogenous DNA repair processes, which can then introduce targeted modifications. The DSB, created by these engineered endonucleases, needs to be repaired and would otherwise be lethal to cells. During the DSB repair, the presence of template DNA can induce site-specific recombination through homology-directed repair (HDR). If no donor DNA is available, the DSB is repaired by non-homologous end joining (NHEJ), which often introduces short DNA insertions or deletions, so called indels, that create 
targeted gene knockouts because the indels can induce a frameshift of amino acid codons, which often results in the formation of a premature stop codon [35]. In general, the frequency of NHEJ is known to be higher compared to that of HDR in most cell types [36].

\section{Use of gene-editing technology in GE pig production}

\section{Gene targeting in somatic cells for GE pig production} Zinc finger nucleases (ZFNs)

Zinc-finger nucleases were the first engineered endonucleases developed by combining DNA recognition ability of zinc-finger (ZF) protein and endonuclease property of FokI enzyme. A ZF protein motif, first identified from Xenopus oocytes while studying the structure of factor IIIA [37], can recognize and bind to three nucleotides, and these ZF proteins can be connected to recognize a longer DNA sequence. Then, these ZF proteins were fused with the chimeric restriction enzyme, FokI, to generate ZFNs [38], which was the beginning of genetic engineering by engineered endonucleases. The incorporation of endonucleases was an essential component of a gene-editing system because previous studies of DNA repair using I-SceI clearly demonstrated that DSBs could enhance the frequency of HR [39-45]. The first demonstration of ZFNs as an effective gene-editing system in mammal was in human cells [5]. The frequency of gene targeting in this study was over $18 \%$ without any selection step; compared to a conventional gene targeting approach, there was 1000-fold increase in targeting efficiency. The study also showed that ZFNs could be successfully used to introduce site-specific mutations through HDR by activating endogenous homologous recombination (HR) pathway.

In 2011, three types of GE pigs were generated using the ZFN technology. The first report of using ZFNs in generating GE pigs was to disrupt hemizygous eGFP gene. A pair of ZFNs could effectively inactivate the eGFP gene in porcine fibroblast cells through NHEJ. The efficiency of the ZFNs was around 5\% [46]. The study showed that the DNA repair processes used for geneediting systems are also present in pig somatic cells, thus, the use of ZFNs is possible in pigs. PPARy was the first endogenous gene to be targeted using ZFN to develop GE pigs for a cardiovascular disease model [47]. In the study, efficiency of three designed ZFN pairs was tested by introducing them into parthenogenetically activated porcine oocytes by microinjection. One ZFN pair was selected from the screening and transfected into porcine cells to disrupt PPAR $\gamma$. Then, heterozygous PPARy knockout pigs were produced through SCNT. Generating knockout cells through the conventional gene targeting approach of using a targeting vector was extremely difficult due to the inefficiency in endogenous HR [32, 48]. However, these two studies demonstrated that ZFNs could effectively establish knockout cells without a targeting vector by relying on endogenous NHEJ system. Furthermore, ZFNs could also disrupt both alleles in pig cells. By transfecting ZFNs and phenotypically selecting $\alpha$-Gal negative cells through fluorescence-activated cell sorting (FACS), GGTA1 was effectively modified at biallelic fashion in porcine fibroblast cells and the cells were developmentally competent via SCNT [49]; the reported efficiency of targeting in this study was $1 \%$. This was a significant achievement in GE pig production because previously only heterozygous modifications were possible through conventional gene targeting strategy.

Use of ZFNs could also lead to production of double knockout pigs without breeding. Two endogenous genes, GGTA1 and CMAH, were inactivated by ZFNs in twosteps. First, both alleles of $C M A H$ gene were disrupted in pig somatic cells. Then, ZFNs targeting GGTA1 were transfected into the cells derived from $C M A H$ knockout clones. Cells were counter-selected for the presence of $\alpha-$ Gal and CMAH/GGTA1 double knockout cells lines were used to generate double knockout pigs through SCNT [50]. This was a significant improvement in xenotransplantation field as ability to disrupt multiples alleles and genes could reduce the number of breedings required to generate GE pigs suitable for xenotransplantation.

These reports utilized the endogenous NHEJ pathway after the DSBs, generated by ZFNs, to disrupt target genes. The first report of using HDR pathway to inactivate an endogenous gene was in 2013 [51]. We successfully disrupted $C M A H$ in porcine fetal fibroblast cells by introducing plasmids coding for ZFNs, and a donor DNA carrying around 800 bp homology to the CMAH on each side and a selectable marker. The length of homology in the donor DNA was shorter compared to the conventional targeting vectors, indicating that the ZFN-induce DSBs could vigorously stimulate the HDR pathway. We also determined that donor DNA carrying longer homology arms resulted in higher frequency of HDR [51]. The cells were used to generate $C M A H$ knockout pigs, showing in vivo competency of the approach.

The application of ZFNs dramatically reduced time required to generate GE pigs [52]. However, ZFNs also presented side effects such as off-site target cutting of the DNA and cytotoxicity, and it was challenging to assemble effective ZFNs pairs. The FokI enzyme, the endonuclease of ZFNs, is supposed to be only activated when dimerized. However, studies demonstrated that FokI could generate DSB at off-site targets as ZFNs combined with wild-type FokI enzyme resulted in unintended DSBs [53-55]. 


\section{TALEN}

Transcription activator-like effector nucleases (TALENs) were developed from plant pathogenic bacteria in Xanthomona [56, 57]. Similar to the ZFN, TALENs need a string of TALEN motifs to bind to the specific locus of DNA on the genome, and FokI enzyme acts as an endonuclease to introduce DSB. The binding domain of TALENs consists of a series of 33-35 amino acid repeats and this one TALEN motif can bind to a single base pair $[58,59]$. TALENs provide more flexibility in target sequences because ZFNs are known to be more active towards GC-rich target regions, whereas TALENs can be assembled to target AT-rich regions and available TALEN kits made it easier to assemble effective TALEN sets [60].

TALENs have been successfully applied in GE pig production. In 2012, the first GE pigs generated using TALENs were reported [61]. The study showed that using a GoldyTALEN set, carrying truncated $\mathrm{N}$ - and C-terminal of TALEN, was more effective in inducing targeted mutations. The TALEN sets were also used to induce targeted mutations during embryogenesis via microinjection in pigs, although no GE pig was produced through this approach. As proof of concept, $L D L R$ knockout pigs were produced through SCNT as a model of familial hypercholesterolemia disorder. The same group also demonstrated that HDR pathway could be successfully utilized during TALEN-mediated gene targeting [62]. TALEN plasmids or mRNA coding for TALENs were transfected into pig fibroblast cells with single-stranded donor DNA of varying lengths (40 - $100 \mathrm{nt})$. Interestingly, using TALEN mRNA resulted in a higher HDR efficiency than TALEN plasmid. Two different knockout pigs, $D A Z L$ and $A P C$, were produced through SCNT to demonstrate in vivo competency of the cells. Intriguingly, we found out that the use of donor DNA could affect the frequency of NHEJ, indicating that there might be cross talk between molecules involved in NHEJ and HDR. The use of donor DNA with longer homology arms in TALEN-mediated gene targeting resulted in a higher percentage of knockout cells modified through NHEJ. [63]. The specific mechanism behind this observation is yet to be determined, but this suggests that the presence of donor DNA could stimulate DNA repair pathways.

Various types of GE pigs, models for xenotransplantation and muscle biology, were developed using TALENs as it could significantly increase the frequency of gene targeting [64-67]. The technology was also used to generate severe combined Immunodeficiency (SCID) pigs for stem cells transplantation study. We produced RAG2 knockout pigs by TALENs and SCNT, and then introduced human induced pluripotent stem (hiPS) cells into the pigs. The pigs presented clear signs of a SCID phenotype and could support growth and differentiation of transplanted hiPS cells by forming teratomas [68]. This was the first report of teratoma formation from human stem cells using non-rodent models, demonstrating that pigs could be an excellent model for studying safety and efficacy in human regenerative medicine research.

\section{CRISPR/Cas9}

The CRISPR array was first reported in 1987. A series of arranged 29 nucleotides as direct repeats with 32 nucleotides as spacing were identified, although the exact function of this array was not determined at the time [69]. Later, this CRISPR array was characterized as an adaptive immune system of bacteria cells against exogenous DNA from virus or plasmid [70, 71]. The ability of the CRISPR/Cas9 system to induce DSBs on a specific sequence of DNA was adopted as an RNA-based geneediting technology. Engineered single guide RNA (sgRNA) combined with tracr-RNA can bind to a target sequence, thus, locating Cas9 protein to the target site on the genome. Then, the Cas9 protein generates DSB to the target site if the protospacer adjacent motif sequence (PAM) is present at the locus [72]. Both ZFN and TALEN require assembling an array to make each set, which is complex and time-consuming [73, 74]. However, CRISPR/Cas9 system is easy to construct because only a 20-bp sgRNA needs to be inserted into a targeting vector [6]. Because of its user-friendly feature, the CRISPR/Cas9 system has become the leading geneediting system. There is a concern of off-site cutting activity using CRISPR/Cas9 system because the system only requires 20 bp recognition $[6,72]$, and allows up to five base pair mismatches for the formation of DSB [75]. Preventative approaches such as using a modified Cas9, which induces a single-strand break instead of DSBs, has been suggested $[6,76]$.

The first application of CRISPR/Cas9 system to target genes in mammalian cells was in 2013 [6]. In pigs, the first use of CRISPR/Cas9 to produce GE pigs was by introducing the system into developing zygotes [77], which will be discussed in more detail in the following section. We first reported that CRISPR/Cas9 system could effectively introduce specific mutations in porcine fibroblast cells for GE pig production [8]. We also attempted to utilize HDR pathway in CRISPR/Cas9-mediated targeting system, although no colonies derived from HDR were identified. In 2015, it was demonstrated that two genes (PINK1 and PINK2) could be simultaneously disrupted using CRISPR/Cas9 system in a single cell [78]; the frequency of multiplexing was $38.1 \%$ in the study. The multiplexing ability of CRISPR/Cas9 system seemed to be an ideal approach to inactivate multiple copies of porcine endogenous retrovirus (PERV) sequences in the pig genome; previous attempts to control PERV activity have not been successful [79-82]. 
Recently, two papers demonstrated that CRISPR/Cas9 system can effectively disrupt multiple copies of PERV in somatic cells and the cells could be used as a donor for SCNT to generate PERV-free pigs [83, 84], indicating that a potential major hurdle of using pigs for xenotransplantation has been lifted using CRISPR/Cas9 system.

The CRISPR/Cas9 system could utilize HDR pathway to place an exogenous DNA into a specific target site as a knock-in strategy [85, 86]. In 2015, a successful knockin strategy was applied to integrate GFP gene into $p H 11$ gene locus, a proposed safe harbor locus; ds-DNA containing $800 \mathrm{bp}$ of homology arms on each side was used as a donor DNA. The efficiency of HDR was 54\% with drug selection. Interestingly, only heterozygous gene knock-in events were observed. This is similar to our previous results using ZFNs [51], indicating higher activity of NHEJ can interfere with obtaining homozygous mutations through HDR.

\section{Direct injection of engineered endonucleases into zygotes to bypass the need for SCNT}

Traditionally, GE pigs carrying site-specific modifications were produced through gene targeting in somatic cells, then SCNT was used to generate the animals. The process has been effective, however, a portion of animals born through this approach have typically had some developmental defects due to SCNT. Recent reports suggest that it is possible to introduce site-specific gene modification through introducing engineered endonucleases into developing embryos, thus, bypassing the need of SCNT.

\section{Knock-out}

TALENs were the first engineered endonucleases to be successfully used to introduce site-specific modifications without applying SCNT [87]. Pigs proposed to be resistant to African Swine Fever Virus were generated through this approach, demonstrating that SCNT is not necessary to introduce site-specific modifications in pigs. The direct injection approach was expanded with the development of CRISPR/Cas9 system, as it is simpler to assemble working sets of CRISPR/Cas9 system, compared to other engineered endonucleases. The first GE pigs generated using microinjection of Cas 9 mRNA and sgRNAs were $v W F$ disrupted pigs [77]). The study reported that Cas 9 mRNA and sgRNA had low cytotoxicity during embryo development; embryo development was similar compared to water-injected embryo. The targeting efficiency through the microinjection was $68 \%$ among piglets born in the study. In the same year, we reported that microinjection of CRISPR/Cas9 system could result in $100 \%$ targeting efficiency [8]. We demonstrated that the approach could generate founders without carrying wild-type allele. The efficacy of CRISPR/Cas9 system during embryogenesis was examined using two genes, CD163 and CD1D. Compared to the previous report, we were able to disrupt all wild-type alleles with a lower concentration of CRISPR/Cas9 RNA (10 ng/ $\mu \mathrm{L}$ of sgRNA and Cas 9 mRNA); higher concentration of the RNA was toxic for embryo survival in this experiment. This could be beneficial as a previous report suggests that lower concentration of RNA help normal development and survival of CRISPR/Cas9 injected embryos [88].

Following studies reported that the microinjection of CRISPR/Cas9 system was effective in producing GE pigs. In 2015, MITF knockout pigs were produced by introducing CRISPR/Cas9 system into in vivo-derived embryos to serve as a melanoma model [89]. Because mature oocytes are transcriptionally inactive, the RNA-based CRISPR/Cas9 system is typically injected into developing embryos. However, it was demonstrated that a plasmid coding for CRISPR/Cas9 could also be effective in generating knockout pigs [90]. GGTA1 knockout pigs for xenotransplantation were produced through this approach; three out of six piglets lacked functional GGTA1 alleles. CRISPR/Cas9 system is also effective in introducing mutations on multiple genes. We demonstrated that the system could disrupt two genes simultaneously at near $100 \%$ efficiency in vitro [8]. The first report of pigs carrying multiple genes was reported in 2016 where parkin/DJ-1/PINK1 were disrupted in an inbred line of pigs using in vivo derived zygotes [91]. Two piglets were born alive and both piglets carried modified target genes but one piglet carried one wild-type allele of parkin. Recently, we reported that the CRISPR/Cas9 system could effectively disrupt two target genes at 100\% targeting efficiency; thus, founder animal could be used for viral challenge studies [7]. In this study, we used in vitro matured oocytes and in vitro fertilized embryos to generate RAG2/IL2RG double knockout pigs. To reduce the cytotoxicity associated with CRISPR/Cas9, we introduced a low concentration of sgRNA $(2.5 \mathrm{ng} / \mu \mathrm{L})$ and Cas 9 mRNA ( $5 \mathrm{ng} / \mu \mathrm{L})$ after optimizing the system.

One of the main concerns related to direct injection of the CRISPR/Cas9 system is the resulting mosaic genotypes. This approach results in high incidents of mosaicism $(20-70 \%)$ in founder rodents and has caused complications in analyzing phenotype of the founders [92-94]. However, only $10-20 \%$ of pigs generated in our previous studies presented a mosaic genotype $[7,8]$. This difference between rodents vs. pigs is not characterized but could be due to disparity in embryo development $[95,96]$ or efficiency of sgRNA and Cas 9 mRNA used in each study.

As shown here, the direct injection of CRISPR/Cas9 system is effective in generating GE pigs. However, in most cases, in vivo derived oocytes or embryos have 


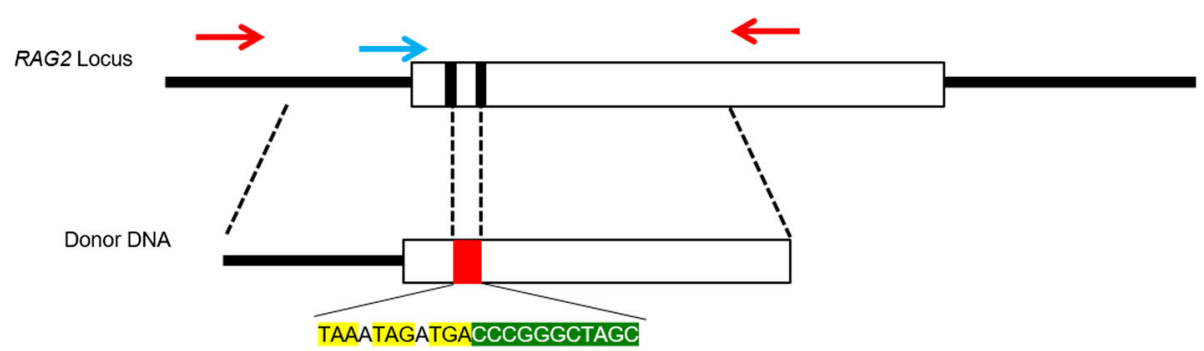

Fig. 1 Strategy of inducing HDR during embryogenesis to disrupt RAG2. Two black bars indicate target sites by CRISPR/Cas9 system on RAG2 exon. Red bar on the donor DNA shows the location of sequences introduced through HDR; yellow sequences are stop codons and green sequences are restriction enzyme sites (Nhel and Smal). Red arrows indicate the location of primers used to amplify the region for genotyping. Blue arrow was used as a primer for Sanger sequencing

been used due to inefficiency in pig in vitro maturation (IVM) and fertilization (IVF). There are only a few papers demonstrating that the approach is possible using in vitro-derived oocytes $[7,8,97]$. In addition, indels introduced through NHEJ do not always result in disruption of target genes. If indels are in triplets, the function of target genes could be retained [7]. With the use of the HDR pathway or further optimization, the issues associated with microinjection approach could be minimized. A recent study demonstrates that high mutagenesis ability of the microinjection approach can also be applied to SCNT embryos [98]. This study showed that by introducing CRISPR/Cas9 system into cloned zygotes, high frequency of targeting was obtained; $100 \%$ biallelic modification in fetuses (6/6) was reported. Introducing CRISPR/Cas9 system into SCNT embryos can be powerful in causing mutations to a specific line of genetic background and reducing the effort required to identify cells carrying targeted modifications.

\section{Knock-in}

The CRISPR/Cas9 system can also stimulate HDR pathway to introduce site-specific modifications at the nucleotide level, when introduced into developing embryos. The HDR based knock-in strategy was first demonstrated by using parthenogenetic embryos in pigs [89]. Over $13 \%$ of the embryos were targeted through HDR by using single-stranded DNA (ssDNA) oligonucleotides with 26 bp homology on each side as a donor. The study also reported that the efficiency of knock-in was highly dependent on the concentration of donor DNA and sgRNA; no HDR event was observed under a lower concentration. In contrast, another study reported that higher concentration of ssDNA could decrease the frequency of HDR-derived modifications in vivo [99]. In the same year, the first successful application of HDR using double-stranded DNA (dsDNA) to generate GE pigs was announced [100]. This study used dsDNA carrying $1 \mathrm{~kb}$ of homologous sequence on each side as a donor DNA to integrate human albumin cDNA into the pig albumin locus. A total of 16 piglets were produced and human albumin gene was detected from all the piglets as a knock-in event.

As mentioned earlier, the frequency of NHEJ is typically higher in most cells compared to that of HDR. A recent report indicates that the use of NHEJ inhibitor can increase the frequency of embryos targeted through HDR [101]. By incubating CRISPR/Cas9 injected embryos with SCR7, a DNA ligase IV inhibitor, the efficiency of HDR was $100 \%$ in parthenogenetic embryos; but no incident of homozygous HDR-derived modifications was reported. The efficiency of knock-in was $40-60 \%$ without the inhibitor. This improvement in the frequency of HDR by the use of an NHEJ inhibitor is consistent with previous reports in rodents [102, 103].

These publications show that utilizing HDR pathway is possible during embryogenesis in pigs, although only a

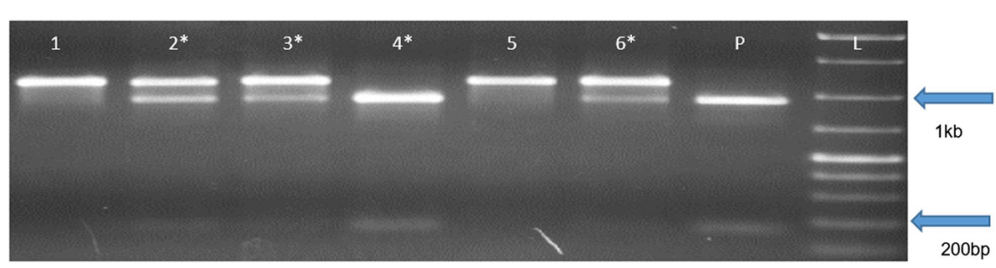

Fig. 2 Genotyping results from single blastocysts injected with CRISPR/Cas9 system. All PCR products were digested with Nhel. PCR product size from wild-type genomic DNA was $1.1 \mathrm{~kb}$. If the embryo carried modified allele through HDR, we expected to see two fragments (950 bp and $160 \mathrm{bp}$ ) after digestion with Nhel. Genomic DNA from an embryo carrying homozygous HDR mutation was served as a positive control (P). * indicates embryos carrying knock-in events. $L$ is a molecular ladder 


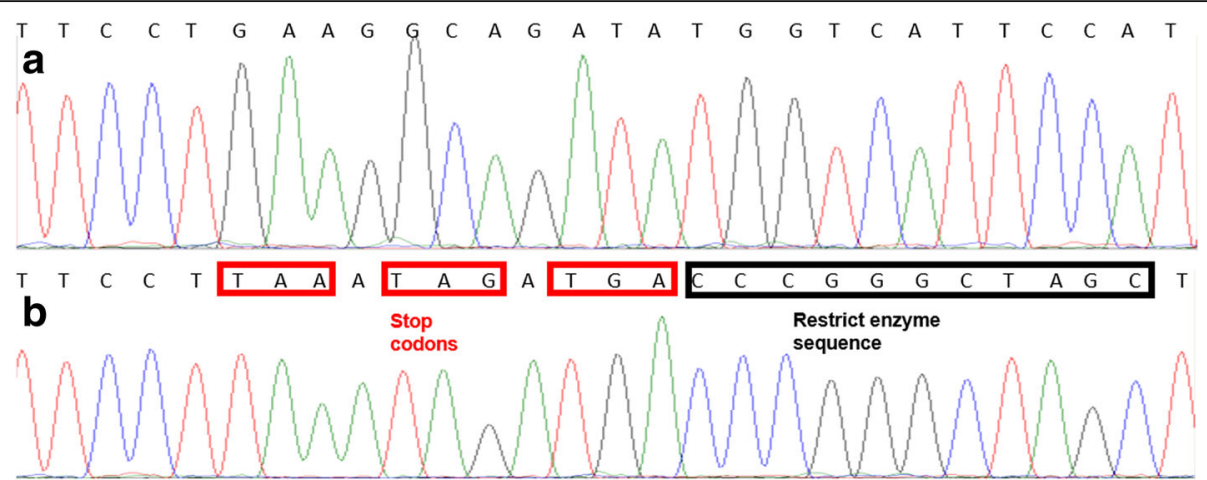

Fig. 3 Chromatogram of genotyping results from (a) wild-type control and (b) embryo carrying knock-in sequence. Direct sequencing of PCR product indicates that this embryo (b) contains homozygous HDR alleles; introduced stop codons and restriction enzyme sequences are highlighted

limited number of publications are available related to this topic. When we tested the efficiency of HDR using RAG2 sgRNAs, previously used to produce $R A G 2 / I L 2 R G$ double knockout pigs, we were able to utilize HDR to introduce specific mutations to the RAG2 locus. A donor DNA containing $800 \mathrm{bp}$ of homologous arms flanking designed stop codons and restrict enzyme sequences [Fig. 1] were introduced with CRISPR/Cas9 RNA into presumptive zygotes. Then, the injected blastocysts were lysed to extract DNA on $\mathrm{d} 7$ post-IVF and PCR was used to identify knock-in events. Sanger sequencing and restriction enzyme digestion of the PCR products indicated that knock-in was successful [Figs. 2 and 3]; the overall efficiency of knock-in was $39.1 \%$ with $8.7 \%$ of the embryos carrying homozygous knock-in alleles (Table 1).

All of the examples above exhibit the power of geneediting systems in producing GE pigs. Proper application of gene-editing systems will effectively reduce the time required to generate GE pigs carrying targeted modifications, thus broadening the use of pig models in biomedicine and agriculture.

\section{Conclusion}

Pig models are becoming a leading gene-edited biomedical model because they are physiologically, anatomically and genetically similar to humans. Rapid generation of GE pigs by utilizing gene-editing technology reduces the cost of

Table 1 A summary of HDR-derived gene-editing on RAG2 locus. This is a summary of three independent replicates. A total of 154 embryos were injected and 28 embryos reached blastocysts on d 7. From 23 blastocysts genotyped, two embryos presented homozygous HDR-derived alleles (8.69\%) and seven embryos carried heterozygous HDR-derived alleles (30.4\%)

\begin{tabular}{ll}
\hline Type of gene-editing events & Frequency, \% \\
\hline Homozygous HDR & 8.69 \\
Heterozygous HDR & 30.4 \\
No HDR & 60.8 \\
\hline
\end{tabular}

housing for the pigs and number of breedings required to obtain enough animals. A recent study shows that geneediting and gene-stacking technology can efficiently generate pigs carrying multiple knockout genes to serve as a model for xenotransplantation [104]. It would take decades to generate these type of pigs through conventional genetic engineering technology. We also demonstrated that founder GE pigs could be used for a viral challenge study; no herd of GE pigs was maintained to produce sufficient number of GE pigs [7]. The gene-editing technology has changed the way GE pigs are produced; however, there are still shortcomings or concerns related to this approach. Off-site editing can be a concern if design of sgRNA is not ideal. Modifications through NHEJ is hard to predict because the outcome of the modifications is random. Mosaic genotypes generated through direct injection of engineered endonuclease into zygotes could lead to founders with unexpected phenotypes. A number of strategies have been suggested to overcome these shortcomings. Use of Cas9 nickase, modified to introduce only single-stranded breaks, was proposed to minimize complications associated with DSBs $[6,105]$. In addition, recent publications demonstrate that application of Cpf1, another CRISPR/Cas system adopted from another bacterial system, can provide higher diversity to target sequences to overcome limitations of designing effective sgRNAs for the CRISPR/Cas9 system [106]. These advancements in gene-editing technology will further expand the use of pig models in biomedicine and beyond.

\footnotetext{
Abbreviations

CRISPR/Cas9: Components in the Clustered regularly interspaced short palindromic repeat /CRISPR-associated; DSB: Double-strand breaks;

ES: Embryonic stem cells; GE: Genetically engineered; GFP: Green fluorescent protein; HDR: Homology direct repair; HR: Homologous recombination; Indel: Insertions or deletions; iPS: Induced pluripotent stem cells; IVF: in vitro fertilization; IVM: in vitro maturation; NHEJ: Non-homologous end joining; PAM: Protospacer adjacent motif sequence; SCID: Severe combined Immunodeficiency; SCNT: Somatic cell nuclear transfer; sgRNA: Single guide RNA; TALENs: Transcription activator-like effector nucleases: tracr-RNA: Trans-activating crRNA; ZFNs: Zinc-Finger Nucleases
} 


\section{Acknowledgements}

Not applicable.

\section{Funding}

The authors would like to acknowledge funding from the National Institutes of Health R21OD019934 (KL) and U42OD011140 (RSP).

\section{Availability of data and materials}

Data sharing not applicable to this article as no datasets were generated or analysed during the current study.

\section{Authors' contributions}

$J R$ conducted experiments in the manuscript. JR, RSP, and KL wrote the manuscript. All authors read and approved the final manuscript.

\section{Ethics approval}

All recombinant DNA work was approved by IBC protocol 17-003.

\section{Competing interests}

The authors have no conflict of interest to declare.

\section{Author details}

'Department of Animal and Poultry Sciences, Virginia Tech, 175 W. Campus Drive, Blacksburg, VA 24061, USA. ²Division of Animal Science, University of Missouri-Columbia, 920 East Campus Drive, Columbia, MO 65211, USA. ${ }^{3}$ National Swine Resource and Research Center, University of Missouri-Columbia, Columbia, MO 65211, USA.

\section{Received: 22 June 2017 Accepted: 22 December 2017}

\section{Published online: 29 January 2018}

\section{References}

1. te Riele $H$, Maandag ER, Berns A. Highly efficient gene targeting in embryonic stem cells through homologous recombination with isogenic DNA constructs. Proc Natl Acad Sci U S A. 1992;89:5128-32.

2. Verma N, Rettenmeier AW, Schmitz-Spanke S. Recent advances in the use of Sus Scrofa (pig) as a model system for proteomic studies. Proteomics. 2011; 11:776-93.

3. Wells KD, Prather RS. Genome-editing technologies to improve research, reproduction, and production in pigs. Mol Reprod Dev. 2017:84(9):1012-7.

4. Rogers CS, Stoltz DA, Meyerholz DK, Ostedgaard LS, Rokhlina T, Taft PJ, et al. Disruption of the CFTR gene produces a model of cystic fibrosis in newborn pigs. Science. 2008;321:1837-41.

5. Urnov FD, Miller JC, Lee YL, Beausejour CM, Rock JM, Augustus S, et al Highly efficient endogenous human gene correction using designed zincfinger nucleases. Nature. 2005:435:646-51.

6. Cong L, Ran FA, Cox D, Lin S, Barretto R, Habib N, et al. Multiplex genome engineering using CRISPR/Cas systems. Science. 2013;339:819-23.

7. Lei S, Ryu J, Wen K, Twitchell E, Bui T, Ramesh A, et al. Increased and prolonged human norovirus infection in RAG2/IL2RG deficient gnotobiotic pigs with severe combined immunodeficiency. Sci Rep. 2016;6:25222.

8. Whitworth KM, Lee K, Benne JA, Beaton BP, Spate LD, Murphy SL, et al. Use of the CRISPR/Cas9 system to produce genetically engineered pigs from in vitro-derived oocytes and embryos. Biol Reprod. 2014;91:78

9. Wang H, Yang H, Shivalila CS, Dawlaty MM, Cheng AW, Zhang F, et al. Onestep generation of mice carrying mutations in multiple genes by CRISPR/ Cas-mediated genome engineering. Cell. 2013:153:910-8.

10. Brackett BG, Baranska W, Sawicki W, Koprowski H. Uptake of heterologous genome by mammalian spermatozoa and its transfer to ova through fertilization. Proc Natl Acad Sci U S A. 1971;68:353-7.

11. Jaenisch R, Mintz B. Simian virus 40 DNA sequences in DNA of healthy adult mice derived from preimplantation blastocysts injected with viral DNA. Proc Natl Acad Sci U S A. 1974;71:1250-4.

12. Gordon JW, Scangos GA, Plotkin DJ, Barbosa JA, Ruddle FH. Genetic transformation of mouse embryos by microinjection of purified DNA. Proc Natl Acad Sci U S A. 1980;77:7380-4.

13. Yokoyama T, Copeland NG, Jenkins NA, Montgomery CA, Elder FF, Overbeek PA. Reversal of left-right asymmetry: a situs inversus mutation. Science. 1993;260:679-82.
14. Hammer RE, Pursel VG, Rexroad CE Jr, Wall RJ, Bolt DJ, Ebert KM, et al. Production of transgenic rabbits, sheep and pigs by microinjection. Nature. 1985:315:680-3.

15. Nagashima H, Fujimura T, Takahagi Y, Kurome M, Wako N, Ochiai T, et al. Development of efficient strategies for the production of genetically modified pigs. Theriogenology. 2003:59:95-106.

16. Uchida M, Shimatsu Y, Onoe K, Matsuyama N, Niki R, Ikeda JE, et al. Production of transgenic miniature pigs by pronuclear microinjection. Transgenic Res. 2001;10:577-82.

17. Doetschman T, Gregg RG, Maeda N, Hooper ML, Melton DW, Thompson S, et al. Targetted correction of a mutant HPRT gene in mouse embryonic stem cells. Nature. 1987;330:576-8.

18. West DB, Pasumarthi RK, Baridon B, Djan E, Trainor A, Griffey SM, et al. A lacZ reporter gene expression atlas for 313 adult KOMP mutant mouse lines. Genome Res. 2015:25:598-607.

19. Ezashi T, Telugu BP, Alexenko AP, Sachdev S, Sinha S, Roberts RM Derivation of induced pluripotent stem cells from pig somatic cells. Proc Natl Acad Sci U S A. 2009;106:10993-8.

20. Koh S, Piedrahita JA. From "ES-like" cells to induced pluripotent stem cells: a historical perspective in domestic animals. Theriogenology. 2014;81:103-11.

21. Anderson GB, Choi SJ, Bondurant RH. Survival of porcine inner cell masses in culture and after injection into blastocysts. Theriogenology. 1994;42:204-12.

22. Hao Y, Wax D, Zhong Z, Murphy C, Ross JW, Rieke A, et al. Porcine skinderived stem cells can serve as donor cells for nuclear transfer. Cloning Stem Cells. 2009;11:101-10.

23. Willadsen SM. Nuclear transplantation in sheep embryos. Nature. 1986;320: 63-5.

24. Prather RS, Barnes FL, Sims MM, Robl JM, Eyestone WH, First NL. Nuclear transplantation in the bovine embryo: assessment of donor nuclei and recipient oocyte. Biol Reprod. 1987:37:859-66.

25. Prather RS, Sims MM, First NL. Nuclear transplantation in early pig embryos. Biol Reprod. 1989:41:414-8.

26. Sims M, First NL. Production of calves by transfer of nuclei from cultured inner cell mass cells. Proc Natl Acad Sci U S A. 1994;91:6143-7.

27. Campbell KH, McWhir J, Ritchie WA, Wilmut I. Sheep cloned by nuclear transfer from a cultured cell line. Nature. 1996:380:64-6.

28. Wilmut I, Schnieke AE, McWhir J, Kind AJ, Campbell KH. Viable offspring derived from fetal and adult mammalian cells. Nature. 1997:385:810-3.

29. Schnieke AE, Kind AJ, Ritchie WA, Mycock K, Scott AR, Ritchie M, et al. Human factor IX transgenic sheep produced by transfer of nuclei from transfected fetal fibroblasts. Science. 1997;278:2130-3.

30. Denning C, Burl S, Ainslie A, Bracken J, Dinnyes A, Fletcher J, et al. Deletion of the alpha(1,3)galactosyl transferase (GGTA1) gene and the prion protein (PrP) gene in sheep. Nat Biotechnol. 2001;19:559-62.

31. Park KW, Cheong HT, Lai L, Im GS, Kuhholzer B, Bonk A, et al. Production of nuclear transfer-derived swine that express the enhanced green fluorescent protein. Anim Biotechnol. 2001;12:173-81.

32. Lai L, Kolber-Simonds D, Park KW, Cheong HT, Greenstein JL, Im GS, et al. Production of alpha-1,3-galactosyltransferase knockout pigs by nuclear transfer cloning. Science. 2002;295:1089-92.

33. Redel BK, O'Gorman C, Prather RS, Whitworth KM. Gene editing to create agricultural and biomedical swine models. In: Appasani K, editor. Genome editing and engineering: from Talens, ZFNs and CRISPRs to molecular surgery. England: Cambridge University Press; 2017. In press (March 2017).

34. Watson AL, Carlson DF, Largaespada DA, Hackett PB, Fahrenkrug SC. Engineered swine models of cancer. Front Genet. 2016;7:78.

35. Christian M, Cermak T, Doyle EL, Schmidt C, Zhang F, Hummel A, et al. Targeting DNA double-strand breaks with TAL effector nucleases. Genetics. 2010;186:757-61.

36. Sonoda E, Hochegger H, Saberi A, Taniguchi $Y$, Takeda S. Differential usage of non-homologous end-joining and homologous recombination in double strand break repair. DNA Repair (Amst). 2006;5:1021-9.

37. Miller J, Mclachlan AD, Klug A. Repetitive zinc-binding domains in the protein transcription factor liia from Xenopus Oocytes. EMBO J. 1985:4: 1609-14.

38. Kim YG, Cha J, Chandrasegaran S. Hybrid restriction enzymes: zinc finger fusions to Fok I cleavage domain. Proc Natl Acad Sci U S A. 1996:93:1156-60.

39. Choulika A, Perrin A, Dujon B, Nicolas JF. Induction of homologous recombination in mammalian chromosomes by using the I-Scel system of Saccharomyces Cerevisiae. Mol Cell Biol. 1995;15:1968-73. 
40. Cohen-Tannoudji M, Robine S, Choulika A, Pinto D, El Marjou F, Babinet C, et al. I-Scel-induced gene replacement at a natural locus in embryonic stem cells. Mol Cell Biol. 1998;18:1444-8.

41. Elliott B, Richardson C, Winderbaum J, Nickoloff JA, Jasin M. Gene conversion tracts from double-strand break repair in mammalian cells. Mol Cell Biol. 1998; 18:93-101.

42. Osman F, Subramani S. Double-strand break-induced recombination in eukaryotes. Prog Nucleic Acid Res Mol Biol. 1998;58:263-99.

43. Plessis A, Perrin A, Haber JE, Dujon B. Site-specific recombination determined by I-Scel, a mitochondrial group I intron-encoded endonuclease expressed in the yeast nucleus. Genetics. 1992;130:451-60.

44. Richardson C, Moynahan ME, Jasin M. Double-strand break repair by interchromosomal recombination: suppression of chromosomal translocations. Genes Dev. 1998;12:3831-42.

45. Segal DJ, Carroll D. Endonuclease-induced, targeted homologous extrachromosomal recombination in Xenopus oocytes. Proc Natl Acad Sci U S A. 1995;92:806-10.

46. Whyte JJ, Zhao J, Wells KD, Samuel MS, Whitworth KM, Walters EM, et al. Gene targeting with zinc finger nucleases to produce cloned eGFP knockout pigs. Mol Reprod Dev. 2011;78:2.

47. Yang D, Yang H, Li W, Zhao B, Ouyang Z, Liu Z, et al. Generation of PPARgamma mono-allelic knockout pigs via zinc-finger nucleases and nuclear transfer cloning. Cell Res. 2011;21:979-82.

48. Rogers CS, Hao Y, Rokhlina T, Samuel M, Stoltz DA, Li Y, et al. Production of CFTR-null and CFTR-DeltaF508 heterozygous pigs by adeno-associated virusmediated gene targeting and somatic cell nuclear transfer. J Clin Invest. 2008;118:1571-7.

49. Hauschild J, Petersen B, Santiago Y, Queisser AL, Carnwath JW, Lucas-Hahn $A$, et al. Efficient generation of a biallelic knockout in pigs using zinc-finger nucleases. Proc Natl Acad Sci U S A. 2011;108:12013-7.

50. Lutz AJ, Li P, Estrada JL, Sidner RA, Chihara RK, Downey SM, et al. Double knockout pigs deficient in N-glycolylneuraminic acid and galactose alpha1,3-galactose reduce the humoral barrier to xenotransplantation. Xenotransplantation. 2013;20:27-35

51. Kwon DN, Lee K, Kang MJ, Choi YJ, Park C, Whyte JJ, et al. Production of biallelic CMP-Neu5Ac hydroxylase knock-out pigs. Sci Rep. 2013;3:1981.

52. Whyte JJ, Prather RS. Cell biology symposium: zinc finger nucleases to create custom-designed modifications in the swine (Sus Scrofa) genome. J Anim Sci. 2012;90:1111-7.

53. Miller JC, Holmes MC, Wang J, Guschin DY, Lee YL, Rupniewski I, et al. An improved zinc-finger nuclease architecture for highly specific genome editing. Nat Biotechnol. 2007;25:778-85.

54. Szczepek M, Brondani V, Buchel J, Serrano L, Segal DJ, Cathomen T. Structure-based redesign of the dimerization interface reduces the toxicity of zinc-finger nucleases. Nat Biotechnol. 2007;25:786-93.

55. Pruett-Miller SM, Connelly JP, Maeder ML, Joung JK, Porteus MH. Comparison of zinc finger nucleases for use in gene targeting in mammalian cells. Mol Ther. 2008;16:707-17.

56. Gohre $\mathrm{V}$, Robatzek S. Breaking the barriers: microbial effector molecules subvert plant immunity. Annu Rev Phytopathol. 2008;46:189-215.

57. Kay S, Bonas U. How Xanthomonas type III effectors manipulate the host plant. Curr Opin Microbiol. 2009;12:37-43.

58. Deng D, Yan C, Pan X, Mahfouz M, Wang J, Zhu JK, et al. Structural basis for sequence-specific recognition of DNA by TAL effectors. Science. 2012;335: 720-3.

59. Moscou MJ, Bogdanove AJ. A simple cipher governs DNA recognition by TAL effectors. Science. 2009;326:1501.

60. Cermak T, Doyle EL, Christian M, Wang L, Zhang Y, Schmidt C, et al. Efficient design and assembly of custom TALEN and other TAL effector-based constructs for DNA targeting. Nucleic Acids Res. 2011;39:e82.

61. Carlson DF, Tan W, Lillico SG, Stverakova D, Proudfoot C, Christian M, et al. Efficient TALEN-mediated gene knockout in livestock. Proc Natl Acad Sci U S A. 2012;109:17382-7.

62. Tan W, Carlson DF, Lancto CA, Garbe JR, Webster DA, Hackett PB, et al. Efficient nonmeiotic allele introgression in livestock using custom endonucleases. Proc Natl Acad Sci U S A. 2013;110:16526-31.

63. Beaton BP, Kwon DN, Choi YJ, Kim JH, Samuel MS, Benne JA, et al. Inclusion of homologous DNA in nuclease-mediated gene targeting facilitates a higher incidence of bi-allelically modified cells. Xenotransplantation. 2015;22:379-90.

64. Miyagawa S, Matsunari H, Watanabe M, Nakano K, Umeyama K, Sakai R, et al. Generation of alpha1,3-galactosyltransferase and cytidine monophospho-N- acetylneuraminic acid hydroxylase gene double-knockout pigs. J Reprod Dev. 2015;61:449-57.

65. Cheng W, Zhao H, Yu H, Xin J, Wang J, Zeng L, et al. Efficient generation of GGTA1-null Diannan miniature pigs using TALENs combined with somatic cell nuclear transfer. Reprod Biol Endocrinol. 2016;14:77.

66. Kang JT, Kwon DK, Park AR, Lee EJ, Yun YJ, Ji DY, et al. Production of alpha1,3-galactosyltransferase targeted pigs using transcription activator-like effector nuclease-mediated genome editing technology. J Vet Sci. 2016; 17:89-96.

67. Rao S, Fujimura T, Matsunari H, Sakuma T, Nakano K, Watanabe M, et al. Efficient modification of the myostatin gene in porcine somatic cells and generation of knockout piglets. Mol Reprod Dev. 2016;83:61-70.

68. Lee K, Kwon DN, Ezashi T, Choi YJ, Park C, Ericsson AC, et al. Engraftment of human iPS cells and allogeneic porcine cells into pigs with inactivated RAG2 and accompanying severe combined immunodeficiency. Proc Natl Acad Sci U S A. 2014;111:7260-5.

69. Ishino Y, Shinagawa H, Makino K, Amemura M, Nakata A. Nucleotide sequence of the iap gene, responsible for alkaline phosphatase isozyme conversion in Escherichia Coli, and identification of the gene product. J Bacteriol. 1987;169:5429-33.

70. Horvath P, Barrangou R. CRISPR/Cas, the immune system of bacteria and archaea. Science. 2010;327:167-70.

71. Wiedenheft B, Sternberg SH, Doudna JA. RNA-guided genetic silencing systems in bacteria and archaea. Nature. 2012;482:331-8.

72. Jinek M, Chylinski K, Fonfara I, Hauer M, Doudna JA, Charpentier E. A programmable dual-RNA-guided DNA endonuclease in adaptive bacterial immunity. Science. 2012;337:816-21.

73. Ellis BL, Hirsch ML, Porter SN, Samulski RJ, Porteus MH. Zinc-finger nucleasemediated gene correction using single AAV vector transduction and enhancement by Food and Drug Administration-approved drugs. Gene Ther. 2013;20:35-42.

74. Holkers M, Maggio I, Liu J, Janssen JM, Miselli F, Mussolino C, et al. Differential integrity of TALE nuclease genes following adenoviral and lentiviral vector gene transfer into human cells. Nucleic Acids Res. 2013;41:e63.

75. Fu Y, Foden JA, Khayter C, Maeder ML, Reyon D, Joung JK, et al. Highfrequency off-target mutagenesis induced by CRISPR-Cas nucleases in human cells. Nat Biotechnol. 2013;31:822-6.

76. Ran FA, Hsu PD, Lin CY, Gootenberg JS, Konermann S, Trevino AE, et al. Double nicking by RNA-guided CRISPR Cas9 for enhanced genome editing specificity. Cell. 2013;154:1380-9.

77. Hai T, Teng F, Guo R, Li W, Zhou Q. One-step generation of knockout pigs by zygote injection of CRISPR/Cas system. Cell Res. 2014;24:372-5.

78. Zhou X, Xin J, Fan N, Zou Q, Huang J, Ouyang Z, et al. Generation of CRISPR/Cas9-mediated gene-targeted pigs via somatic cell nuclear transfer. Cell Mol Life Sci. 2015;72:1175-84.

79. Ramsoondar J, Vaught T, Ball S, Mendicino M, Monahan J, Jobst P, et al. Production of transgenic pigs that express porcine endogenous retrovirus small interfering RNAs. Xenotransplantation. 2009;16:164-80.

80. Semaan M, Kaulitz D, Petersen B, Niemann H, Denner J. Long-term effects of PERVspecific RNA interference in transgenic pigs. Xenotransplantation. 2012;19:112-21.

81. Fiebig U, Stephan O, Kurth R, Denner J. Neutralizing antibodies against conserved domains of p15E of porcine endogenous retroviruses: basis for a vaccine for xenotransplantation? Virology. 2003;307:406-13.

82. Semaan M, Ivanusic D, Denner J. Cytotoxic effects during knock out of multiple porcine endogenous retrovirus (PERV) sequences in the pig genome by zinc finger nucleases (ZFN). PLoS One. 2015;10:e0122059.

83. Yang L, Guell M, Niu D, George H, Lesha E, Grishin D, et al. Genome-wide inactivation of porcine endogenous retroviruses (PERVs). Science. 2015; 350:1101-4.

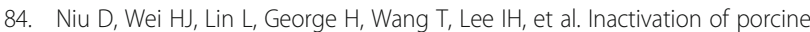
endogenous retrovirus in pigs using CRISPR-Cas9. Science. 2017;357(6357): 1303-7.

85. Ruan J, Li H, Xu K, Wu T, Wei J, Zhou R, et al. Highly efficient CRISPR/Cas9mediated transgene knockin at the $\mathrm{H} 11$ locus in pigs. Sci Rep. 2015;5:14253.

86. Sato M, Kagoshima A, Saitoh I, Inada E, Miyoshi K, Ohtsuka M, et al. Generation of alpha-1,3-Galactosyltransferase-deficient porcine embryonic fibroblasts by CRISPR/Cas9-mediated knock-in of a small mutated sequence and a targeted toxin-based selection system. Reprod Domest Anim. 2015;50:872-80

87. Lillico SG, Proudfoot C, Carlson DF, Stverakova D, Neil C, Blain C, et al. Live pigs produced from genome edited zygotes. Sci Rep. 2013;3:2847. 
88. Brinster RL, Chen HY, Trumbauer ME, Yagle MK, Palmiter RD. Factors affecting the efficiency of introducing foreign DNA into mice by microinjecting eggs. Proc Natl Acad Sci U S A. 1985;82:4438-42.

89. Wang X, Zhou J, Cao C, Huang J, Hai T, Wang Y, et al. Efficient CRISPR/Cas9mediated biallelic gene disruption and site-specific knockin after rapid selection of highly active sgRNAs in pigs. Sci Rep. 2015;5:13348.

90. Petersen B, Frenzel A, Lucas-Hahn A, Herrmann D, Hassel P, Klein S, et al. Efficient production of biallelic GGTA1 knockout pigs by cytoplasmic microinjection of CRISPR/Cas9 into zygotes. Xenotransplantation. 2016; 23:338-46.

91. Wang X, Cao C, Huang J, Yao J, Hai T, Zheng Q, et al. One-step generation of triple gene-targeted pigs using CRISPR/Cas9 system. Sci Rep. 2016;6:20620.

92. Mizuno S, Dinh TT, Kato K, Mizuno-lijima S, Tanimoto Y, Daitoku Y, et al. Simple generation of albino C57BL/6J mice with G291T mutation in the tyrosinase gene by the CRISPR/Cas9 system. Mamm Genome. 2014;25:327-34.

93. Yen ST, Zhang M, Deng JM, Usman SJ, Smith CN, Parker-Thornburg J, et al. Somatic mosaicism and allele complexity induced by CRISPR/Cas9 RNA injections in mouse zygotes. Dev Biol. 2014;393:3-9.

94. Oliver D, Yuan S, McSwiggin H, Yan W. Pervasive genotypic Mosaicism in founder mice derived from genome editing through pronuclear injection. PLoS One. 2015;10:e0129457.

95. Cockburn K, Rossant J. Making the blastocyst: lessons from the mouse. J Clin Invest. 2010;120:995-1003.

96. Isom SC, Li RF, Whitworth KM, Prather RS. Timing of first embryonic cleavage is a positive indicator of the in vitro developmental potential of porcine embryos derived from in vitro fertilization, somatic cell nuclear transfer and parthenogenesis. Mol Reprod Dev. 2012;79:197-207.

97. Whitworth KM, Benne JA, Spate LD, Murphy SL, Samuel MS, Murphy CN, et al, Zygote injection of CRISPR/Cas9 RNA successfully modifies the target gene without delaying blastocyst development or altering the sex ratio in pigs. Transgenic Res. 2017;26:97-107.

98. Sheets TP, Park CH, Park KE, Powell A, Donovan DM, Telugu BP. Somatic cell nuclear transfer followed by CRIPSR/Cas9 microinjection results in highly efficient genome editing in cloned pigs. Int J Mol Sci. 2016;17(12):2031.

99. Zhou X, Wang L, Du Y, Xie F, Li L, Liu Y, et al. Efficient generation of genemodified pigs harboring precise Orthologous human mutation via CRISPR/ Cas9-induced homology-directed repair in zygotes. Hum Mutat. 2016;37: $110-8$.

100. Peng J, Wang Y, Jiang J, Zhou X, Song L, Wang L, et al. Production of human albumin in pigs through CRISPR/Cas9-mediated Knockin of human cDNA into swine albumin locus in the zygotes. Sci Rep. 2015;5:16705.

101. Park KE, Powell A, Sandmaier SE, Kim CM, Mileham A, Donovan DM, et al. Targeted gene knock-in by CRISPR/Cas ribonucleoproteins in porcine zygotes. Sci Rep. 2017;7:42458.

102. Maruyama T, Dougan SK, Truttmann MC, Bilate AM, Ingram JR, Ploegh HL. Increasing the efficiency of precise genome editing with CRISPR-Cas9 by inhibition of nonhomologous end joining. Nat Biotechnol. 2015;33:538-42.

103. Chu VT, Weber T, Wefers B, Wurst W, Sander S, Rajewsky K, et al. Increasing the efficiency of homology-directed repair for CRISPR-Cas9-induced precise gene editing in mammalian cells. Nat Biotechnol. 2015;33:543-8.

104. Fischer K, Kraner-Scheiber S, Petersen B, Rieblinger B, Buermann A, Flisikowska T, et al. Efficient production of multi-modified pigs for xenotransplantation by 'combineering', gene stacking and gene editing. Sci Rep. 2016;6:29081.

105. Gasiunas G, Barrangou R, Horvath P, Siksnys V. Cas9-crRNA ribonucleoprotein complex mediates specific DNA cleavage for adaptive immunity in bacteria. Proc Natl Acad Sci U S A. 2012;109:E2579-86.

106. Zetsche B, Gootenberg JS, Abudayyeh OO, Slaymaker IM, Makarova KS, Essletzbichler P, et al. Cpf1 is a single RNA-guided endonuclease of a class 2 CRISPR-Cas system. Cell. 2015:163:759-71.

\section{Submit your next manuscript to BioMed Central and we will help you at every step:}

- We accept pre-submission inquiries

- Our selector tool helps you to find the most relevant journal

- We provide round the clock customer support

- Convenient online submission

- Thorough peer review

- Inclusion in PubMed and all major indexing services

- Maximum visibility for your research

Submit your manuscript at www.biomedcentral.com/submit
Biomed Central 